\title{
ARMAZENAMENTO A VÁCUO DE SEMENTE DE MILHO DOCE ${ }^{1}$
}

\author{
REGINALDO DE CAMARGO², MARIA LAENE MOREIRA DE CARVALHO³
}

\begin{abstract}
RESUMO - Para avaliar os efeitos de diferentes tipos de embalagens e ambientes sobre a qualidade de semente de milho doce armazenadas por um período de 18 meses, foram testadas três tipos de embalagens : papel tipo kraft trifoliado, embalagem plástica e acondicionamento a vácuo ( $0,1 \mathrm{~atm})$. No caso da embalagem de papel, parte das sementes recebeu tratamento com fungicida e inseticidas. Para as sementes acondicionadas em embalagens impermeáveis, foram testados dois níveis de umidade de semente para o armazenamento: $8,0 \%$ e 11,0\%. As sementes foram armazenadas sob condição de câmara refrigerada ou armazém convencional, tendo sua qualidade avaliada pelos testes de germinação, índice de velocidade de emergência, teste de frio, alterações nos sistemas enzimáticos ADH e MDH e teste de sanidade. Verificou-se que a condição de câmara refrigerada é a mais eficiente para a preservação da qualidade fisiológica de semente de milho doce, condição na qual o acondicionamento de sementes tratadas em embalagem de papel ou plástico foram os métodos mais eficientes para a preservação. Para o armazenamento em condições de ambiente natural, o acondicionamento a vácuo ou em embalagem plástica assegura menores reduções na qualidade fisiológica da semente após 18 meses. A incidência dos fungos Fusarium moniliforme e Aspergillus sp., em câmara refrigerada, e Aspergillus sp., em armazém convencional, é favorecida, independente do tipo de embalagem no armazenamento de semente de milho doce não tratadas com fungicida.
\end{abstract}

Termos para indexação: armazenamento, vácuo, embalagem.

\section{SWEET CORN SEED STORAGE}

\begin{abstract}
This study evaluated the effect of different packaging types and storage environments on sweet corn quality after 18 months of storage. Three types of packaging were evaluated: threelayered Kraft paper package, plastic package and vacuum conditioning $(0.1 \mathrm{~atm})$. Seeds stored in paper package were treated with fungicides and insecticides. Two moisture contents were evaluated in the seeds stored in impermeable (plastic) package: 8 and 11\%. The seeds were stored in a cold room or in a conventional warehouse. Seed quality was evaluated using the tests of germination, emergence speed index, cold test, sanitary test and the evaluation of changes in $\mathrm{ADH}$ and MDH enzyme systems. Storage in a cold room was more effective in preserving the physiologic quality of sweet corn seeds, and in this environment, storage of treated seeds in paper or plastic packages was more adequate for seed preservation. Storing sweet corn seeds in a conventional warehouse, packaging under vacuum or in plastic package assured smaller reductions in seed physiologic quality after 18 months. The incidence of the fungi Fusarium moniliforme and Aspergillus sp. in the cold room and Aspergillus sp. In the conventional storage was favored regardless of the type of package in the storage of sweet corn seeds that were not treated with fungicides.
\end{abstract}

Index terms: storage, vacuum, packaging.

${ }^{1}$ Submetido em 16/04/2007. Aceito para publicação em 17/12/2007. Parte da Tese de Doutorado do primeiro autor apresentado a UFLA.

${ }^{2}$ Engenheiro Agrônomo, Doutor, Prof. da Universidade Federal de Uberlândia - Instituto de Ciências Agrárias. Campus Umuarama, Bloco 2E
CEP: 38405-302 - Uberlândia - MG. rcamargo@umuarama.ufu.br

${ }^{3}$ Engenheira Agrônoma, PhD, Prof ${ }^{\text {a }}$ do Departamento de Fitotecnia da Universidade Federal de Lavras. 


\section{INTRODUÇÃO}

A semente de milho doce apresenta elevados teores de açúcares no endosperma, em detrimento ao amido. Essa característica, explorada em especial pela indústria de conservas e enlatados, em substituição ao milho comum, é condicionada por um conjunto de genes, os quais, individualmente ou em conjunto, podem promover variações marcantes como textura, formato e composição do endosperma. Além da composição química, algumas das diferenças em relação ao milho comum fazem com que a semente de milho doce seja considerada como problemática, principalmente em relação à sua tolerância ao armazenamento e ao baixo vigor da semente (Azanza et al., 1996), a ponto de ser tolerado um limite mínimo de $65 \%$ de germinação para comercialização de semente certificada. A semente de milho doce, geralmente, é desuniforme e mais sujeita a danos do que a semente de milho comum, além de apresentar disfunção no escutelo, em relação ao metabolismo e ao uso de carboidratos (Styer e Cantliffe, 1983). A fragilidade do sistema de membranas após a secagem, características texturais do endosperma, a susceptibilidade a fungos patogênicos e a menor concentração de reservas são ainda citadas como características que contribuem para a baixa qualidade dessa semente (Guiscem et al., 2001). Tais características têm sido objeto de novas investigações, incluindo estudos relativos ao processo de maturação dessa semente (Araújo, 2006).

Fungos de diversos gêneros, como Fusarium, Penicillium e Rhizopus, podem ser encontrados em crescimento ou esporulando em espigas antes da colheita das sementes (Marshall, 1987) e, em adição à contaminação superficial, diferentes fungos colonizam o interior da semente como Fusarium moniliforme J. Sheld e Penicillium oxalicum Currie e Thom (Wilson e Mohan, 1991). Associados, esses e outros fungos podem acelerar o processo de deterioração da semente, durante o armazenamento. A taxa de deterioração da semente, ao longo do período em que permanece armazenada, sofre influência de vários fatores, muito embora, a temperatura e a umidade relativa do ar ambiente sejam comumente citadas como os mais importantes (Smith e Berjak, 1995). Diversos trabalhos envolvendo variações na temperatura e umidade relativa do ar, durante o armazenamento de semente de milho, evidenciaram que uma das combinações ideais para a conservação, por períodos curtos entre a colheita e a semeadura, seria a proporcionada por semente com $12,0 \%$ a $13,0 \%$ de água, em ambiente sob temperatura $20^{\circ} \mathrm{C}$ e umidade relativa do ar abaixo de 60\% (Delouche e Baskin, 1973; Maeda et al., 1987; Oliveira, 1997).
A decisão sobre o tipo de embalagem a ser utilizada para o armazenamento de semente também não é tão simples como pode parecer à primeira vista. As condições climáticas sob as quais a semente vai permanecer armazenada a espera da época da semeadura, a modalidade de comercialização da semente em questão, as características mecânicas da embalagem e sua disponibilidade no comércio são aspectos importantes a ser considerados (Carvalho e Nakagawa, 2000). O conteúdo de água e a temperatura de armazenamento da semente podem ser facilmente manipulados pelo processo de secagem e armazenamento em ambiente com umidade e temperatura controladas por equipamentos. O conteúdo de oxigênio disponível, por sua vez, pode ser reduzido pelo empacotamento a vácuo, em embalagens impermeáveis seladas, ou pela injeção de um gás livre de oxigênio. As pressões de vácuo utilizadas nos experimentos têm variado desde valores relativamente baixos, como 0,9 kPa(New, 1988), até pressões de $87 \mathrm{kPa}$ (Rouziere, 1986), quase dez vezes a pressão máxima recomendada por Edwin (1961), equivalente $10,13 \mathrm{kPa}$ ou 0,01 atm. Ensaios realizados com semente de abóbora (Bee e Barros, 1999), feijão (Aguirre e Peske, 1991), trigo (Aguirre e Peske, 1991) e amendoim (O’Dowd e Dobie, 1983) indicaram a viabilidade do armazenamento a vácuo. Por outro lado, New (1988) relata que o acondicioamento de semente de soja e milho a vácuo pode resultar em ganhos pouco significativos, o que torna a técnica não recomendável para uso comercial em larga escala. O objetivo deste trabalho foi avaliar os efeitos de diferentes tipos de embalagens e ambientes sobre a qualidade de semente de milho doce, armazenada por um período de 18 meses.

\section{MATERIAL E MÉTODOS}

O experimento foi conduzido no Laboratório de Análise de Sementes da Universidade Federal de Lavras, MG, com utilização de semente do híbrido triplo DO-04 (contendo gene shrunken, que confere o caráter super doce) classificada em peneira de crivo circular com dimensão de 20/64 de polegada. A colheita foi realizada manualmente em espigas, assim que as sementes atingiram grau de umidade próximo a 30,0\%, sendo posteriormente secas à temperatura de $40^{\circ} \mathrm{C}$ (Araújo, 1999) até a umidade de $12,0 \%$ e expurgadas com fosfina. Durante o armazenamento, foram estudados os efeitos do acondicionamento da sementes em embalagens permeáveis (tratadas e não tratadas com fungicida e inseticidas) e impermeáveis (com e sem vácuo), em duas condições de ambiente (armazém convencional e câmara refrigerada). 
A semente acondicionada em embalagens permeáveis (papel tipo kraft trifoliado) foi embalada com grau de umidade de $11,0 \%$. No armazenamento em embalagens impermeáveis (sacos de polietileno), foram estudados os efeitos do acondicionamento em presença e ausência de vácuo (0,1 atm) nas umidades de $8,0 \%$ e $11,0 \%$. Nos tratamentos correspondentes à semente acondicionada em embalagens impermeáveis com umidade de $8,0 \%$, uma nova secagem foi feita antes do armazenamento em um secador estacionário de camada fixa à temperatura de $40^{\circ} \mathrm{C}$. $\mathrm{O}$ empacotamento a vácuo da semente foi realizado com o auxílio de bomba de vácuo ajustada para fornecer pressão de 0,1 atm.

Parte da semente armazenada em sacos de papel foi submetida ao tratamento químico com fungicida e inseticidas. Para o tratamento da semente, foi utilizada a mistura contendo o fungicida Captan 750 TS $\left(1,6 \mathrm{~g} . \mathrm{kg}^{-1}\right)$ e os inseticidas K-obiol 2P CE (0,5g . $\left.\mathrm{kg}^{-1}\right)+$ Actellic 500 CE (0,008\%), na dosagem de $8 \mathrm{~mL} . \mathrm{kg}^{-1}$ de sementes. Após embalada, a semente foi mantida em dois ambientes: câmara refrigerada $\left(10^{\circ} \mathrm{C}\right.$ e umidade relativa de $\left.50 \%\right)$ e armazém convencional. A qualidade da semente foi avaliada antes de ser embalada e durante o período de armazenamento aos seis, doze e dezoito meses, constituindo assim quatro épocas de amostragem. As unidades experimentais corresponderam a quatro pacotes de 350 gramas de semente por tratamento, para a cada época de avaliação.

Para a realização do teste de germinação, foram adotados os critérios recomendados nas Regras para Análise de Sementes (Brasil, 1992), exceto pelo número de sementes avaliadas que foi de 200, dividas em quatro repetições. Foram realizadas leituras no quarto e no sétimo dias, após a instalação do teste. Para a determinação do índice de velocidade de germinação (IVE), a semeadura foi realizada em bandejas plásticas contendo uma mistura de areia + terra na proporção de $2: 1$, utilizando quatro repetições de 50 sementes por tratamento. O teste foi conduzido em câmara de germinação ajustada a $25^{\circ} \mathrm{C}$, em regime alternado de luz e escuro (12 horas). A partir do início da emergência, foram feitas avaliações diárias, computando o número de plântulas emergidas (maior que 1 $\mathrm{cm}$ ) até a estabilização do estande (Maguirre, 1962). O teste frio foi conduzido em bandejas plásticas, contendo mistura de $2 / 3$ de areia e 1/3 de terra retirada da camada arável, em área anteriormente cultivada com milho, com ajuste da umidade do substrato para $60 \%$ da capacidade de campo, conforme as prescrições da ISTA (1995). Foram semeadas 50 sementes por bandeja, utilizando-se quatro repetições para cada unidade experimental.
$\mathrm{Na}$ análise isoenzimática, a extração foi efetuada adicionando-se a $100 \mathrm{mg}$ do pó das sementes, $400 \mu 1$ do tampão de extração (0,2M Tris, $0,1 \% \beta$ mercaptoetanol, $0,4 \%$ PVP, 0,4\% PEG, $1 \mathrm{mM}$ EDTA). O homogeneizado foi incubado em gelo por 24 horas e centrifugado a $14.000 \mathrm{xg} \mathrm{a} 4{ }^{\circ} \mathrm{C}$, por 30 minutos. Posteriormente, $20 \mu 1$ do sobrenadante de cada tratamento foram aplicados nos géis de poliacrilamida 7,5\% (gel de separação) e 4,5\% (gel de concentração). A migração foi efetuada a uma corrente de $12 \mathrm{~mA}$ no gel concentrador e $24 \mathrm{~mA}$ no gel separador. Após a eletroforese, os géis foram corados para detecção da atividade das enzimas malato desidrogenase (MDH) e álcool desidrogenase (ADH), de acordo com a metodologia descrita por Alfenas et al. (1991). Para o teste de sanidade, utilizou-se o método de incubação em substrato de papel com congelamento, conforme descrito por Machado (1988). Foram analisadas 200 sementes por tratamento, distribuídas em oito repetições de 25 sementes por placa de Petri de $15 \mathrm{~cm}$ de diâmetro sobre três folhas de papel de filtro umedecidas com água destilada e autoclavada. Após 25 horas de incubação, as placas contendo as sementes foram transferidas para um freezer à temperatura de $-20^{\circ} \mathrm{C}$, onde permaneceram por 24 horas. Em seguida, as placas retornaram à sala de incubação à temperatura de $20^{\circ} \mathrm{C}$, sob regime alternado de 12 horas de luz branca e 12 horas no escuro, durante sete dias. Após esse período, com o auxílio de um microscópio estereoscópico, foi realizada a identificação e a quantificação dos fungos presentes na semente.

Foi utilizado o delineamento inteiramente ao acaso, com quatro repetições, em esquema fatorial $(2 \times 4 \times 6=48)$, correspondente a dois ambientes de armazenamento (câmara refrigerada e armazém convencional) x quatro épocas de avaliação (zero, seis, 12 e 18 meses) x seis métodos de acondicionamento (semente não tratada em embalagem de papel; semente tratada em embalagem de papel; embalagem plástica com $8,0 \%$ de umidade; embalagem plástica com $11,0 \%$ de umidade; condição de vácuo a $8,0 \%$ de umidade; condição de vácuo a $11,0 \%$ de umidade). Os dados referentes aos parâmetros avaliados foram submetidos à análise de variância, aplicando o teste de médias de Scott e Knott $(\mathrm{P}<$ $0,01 \%$ ) para os métodos de acondicionamento, teste de $\mathrm{F}$ ( $\mathrm{P}$ $<0,01$ e $0,05 \%$ ), para ambientes de armazenamento e análise de regressão para épocas de armazenamento.

\section{RESULTADOS E DISCUSSÃO}

Tendo sido estudados os efeitos de diferentes ambientes de armazenamento, métodos de acondicionamento ou embalagem e tempo de armazenamento, foram verificados 
efeitos altamente significativos para todos os fatores isolados, bem como para a interação tripla.

Na primeira contagem do teste de germinação aos quatro dias, a semente armazenada em câmara fria apresentou porcentagens médias de germinação superiores, em relação ao ambiente natural, a partir dos 12 meses (Tabela 1), muito embora já aos seis meses, o ambiente de armazenamento determinasse diferenças para a porcentagem de germinação na contagem final, para os tratamentos de armazenamento em embalagem plástica e a vácuo com $8,0 \%$ de umidade (Tabela 2). A condição de ambiente controlado favorece a conservação da semente, no entanto, há variações entre os resultados dos experimentos. Marincek (2000) não verificou queda na porcentagem de germinação de semente de milho armazenada com $12,0 \%$ de umidade, mesmo aos
12 meses de armazenamento em ambiente natural, quando foram colhidas com 18,0\% de umidade. Oliveira (1997), concluiu que a semente de milho armazenada em condições de armazém convencional em embalagem semipermeável apresentou acentuada redução no nível de vigor, após 18 meses de armazenamento, enquanto que, na condição de câmara refrigerada, a qualidade fisiológica permaneceu quase inalterada. De modo semelhante, no presente trabalho, foi observado que, sob condição de câmara refrigerada, os tratamentos de armazenamento em embalagem de papel se apresentaram entre os melhores com relação à porcentagem de germinação aos quatro dias, em todas as épocas de avaliação, embora na avaliação aos 18 meses, não houvesse diferença significativa entre os tratamentos. Na contagem final do teste de germinação, foi detectada redução na

TABELA 1. Porcentagem de germinação de sementes de milho doce na primeira contagem do teste de germinação aos quatro dias, em função da condição de armazenamento e método de embalagem, antes do armazenamento e aos 6, 12 e 18 meses. UFLA, Lavras, 2007.

\begin{tabular}{|c|c|c|c|c|c|c|c|c|}
\hline \multirow{3}{*}{ Embalagem } & \multicolumn{8}{|c|}{ Tempo de armazenamento/Condição de armazenamento } \\
\hline & \multicolumn{2}{|c|}{ Antes do armazenamento } & \multicolumn{2}{|c|}{6 meses } & \multicolumn{2}{|c|}{12 meses } & \multicolumn{2}{|c|}{18 meses } \\
\hline & Câmara fria & Ambiente & Câmara fria & Ambiente & Câmara fria & Ambiente & Câmara fria & Ambiente \\
\hline Papel tratadas & $64,00 \mathrm{aA}$ & $68,50 \mathrm{aA}$ & $65,00 \mathrm{aA}$ & $60,00 \mathrm{aA}$ & $41,50 \mathrm{Aa}$ & $25,00 \mathrm{bA}$ & $28,00 \mathrm{aA}$ & $15,50 \mathrm{bB}$ \\
\hline Papel N.T** & $59,00 \mathrm{bA}$ & $69,50 \mathrm{aA}$ & $60,50 \mathrm{aA}$ & $51,50 \mathrm{bB}$ & $37,00 \mathrm{aA}$ & $21,50 \mathrm{bB}$ & $26,00 \mathrm{aA}$ & $16,00 \mathrm{bB}$ \\
\hline Plástico $(8 \%)$ & $66,50 \mathrm{aA}$ & $70,00 \mathrm{aA}$ & $45,50 \mathrm{aC}$ & $51,50 \mathrm{aB}$ & $29,50 \mathrm{aB}$ & $29,00 \mathrm{aA}$ & $22,50 \mathrm{aA}$ & $18,00 \mathrm{aB}$ \\
\hline Plástico (11\%) & $64,50 \mathrm{aA}$ & $68,00 \mathrm{aA}$ & $50,00 \mathrm{aB}$ & $56,00 \mathrm{aA}$ & $35,50 \mathrm{aA}$ & $18,00 \mathrm{bB}$ & $23,50 \mathrm{aA}$ & $18,00 \mathrm{aB}$ \\
\hline Vácuo (8\%) & $65,00 \mathrm{aA}$ & $58,50 \mathrm{bB}$ & $51,50 \mathrm{aB}$ & $50,00 \mathrm{aB}$ & $38,50 \mathrm{aA}$ & $28,00 \mathrm{bA}$ & $25,00 \mathrm{aA}$ & $25,00 \mathrm{aA}$ \\
\hline Vácuo (11\%) & $67,50 \mathrm{aA}$ & $66,00 \mathrm{aA}$ & $55,00 \mathrm{aB}$ & $53,00 \mathrm{aB}$ & $38,50 \mathrm{aA}$ & $20,00 \mathrm{bB}$ & $24,00 \mathrm{aA}$ & $21,00 \mathrm{aA}$ \\
\hline
\end{tabular}

* Médias seguidas pela mesma letra minúscula na linha e maiúscula na coluna, dentro de cada tempo de armazenamento, não diferem entre si pelo teste de Scott e Knott para embalagem e F para condição de armazenamento $(\mathrm{P}<0,05)$. ** Papel N.T: Sementes não tratadas em embalagem de papel.

TABELA 2. Porcentagem de germinação de sementes de milho doce no teste de germinação, em função da condição de armazenamento e método de embalagem, antes do armazenamento e aos 6, 12 e 18 meses. UFLA, Lavras, 2007.

\begin{tabular}{|c|c|c|c|c|c|c|c|c|}
\hline \multirow{3}{*}{ Embalagem } & \multicolumn{8}{|c|}{ Tempo de armazenamento/Condição de armazenamento } \\
\hline & \multicolumn{2}{|c|}{$\begin{array}{c}\text { Antes do } \\
\text { armazenamento }\end{array}$} & \multicolumn{2}{|c|}{$\begin{array}{c}6 \text { meses de } \\
\text { armazenamento }\end{array}$} & \multicolumn{2}{|c|}{$\begin{array}{c}12 \text { meses de } \\
\text { armazenamento }\end{array}$} & \multicolumn{2}{|c|}{$\begin{array}{c}18 \text { meses de } \\
\text { armazenamento }\end{array}$} \\
\hline & $\begin{array}{l}\text { Câmara } \\
\text { fria }\end{array}$ & Ambiente & Câmara fria & Ambiente & Câmara fria & Ambiente & Câmara fria & Ambiente \\
\hline Papel tratadas & $77,50 \mathrm{bA}$ & $84,00 \mathrm{aA}$ & $79,50 \mathrm{aA}$ & $81,00 \mathrm{aA}$ & $79,00 \mathrm{aA}$ & $60,50 \mathrm{bB}$ & $78,50 \mathrm{aA}$ & $47,50 \mathrm{bC}$ \\
\hline Papel N.T.** & $80,50 \mathrm{aA}$ & $79,50 \mathrm{aA}$ & $78,00 \mathrm{aA}$ & $76,00 \mathrm{aA}$ & $77,00 \mathrm{aA}$ & $56,50 \mathrm{bB}$ & $74,50 \mathrm{aA}$ & $45,00 \mathrm{bC}$ \\
\hline Plástico $(8 \%)$ & $78,50 \mathrm{aA}$ & $79,00 \mathrm{aA}$ & $74,00 \mathrm{aB}$ & $67,50 \mathrm{bB}$ & $72,00 \mathrm{aA}$ & $66,00 \mathrm{bA}$ & $75,50 \mathrm{aA}$ & $67,00 \mathrm{bA}$ \\
\hline Plástico(11\%) & $79,00 \mathrm{aA}$ & $80,50 \mathrm{aA}$ & $76,00 \mathrm{aA}$ & $76,50 \mathrm{aA}$ & $73,50 \mathrm{aA}$ & $60,50 \mathrm{bB}$ & $74,00 \mathrm{aA}$ & $56,00 \mathrm{bB}$ \\
\hline Vácuo (8\%) & $79,50 \mathrm{aA}$ & $81,00 \mathrm{aA}$ & $70,50 \mathrm{aB}$ & $63,50 \mathrm{bB}$ & $77,50 \mathrm{aA}$ & $67,50 \mathrm{bA}$ & $71,00 \mathrm{aB}$ & $66,50 \mathrm{aA}$ \\
\hline Vácuo $(11 \%)$ & $80,00 \mathrm{aA}$ & $78,50 \mathrm{aA}$ & $76,00 \mathrm{aA}$ & $76,50 \mathrm{aA}$ & $65,00 \mathrm{aB}$ & $64,00 \mathrm{aA}$ & $67,00 \mathrm{aB}$ & $64,50 \mathrm{aA}$ \\
\hline
\end{tabular}

* Médias seguidas pela mesma letra minúscula na linha e maiúscula na coluna, dentro de cada tempo de armazenamento, não diferem entre si pelo teste de Scott e Knott para embalagem e F para condição de armazenamento $(\mathrm{P}<0,05)$. ** Papel N.T: Sementes não tratadas em embalagem de papel. 
qualidade da semente armazenada a vácuo em condição de câmara fria com $8,0 \%$ e $11,0 \%$ de umidade (Tabela 2).

Aos 18 meses de armazenamento, verificou-se que, na condição de ambiente natural, a semente acondicionada em embalagem de papel sofreu as maiores reduções na porcentagem de germinação aos quatro dias, diferindo das mantidas em embalagem plástica apenas na contagem final. Em contrapartida, as embalagens a vácuo se mostraram eficientes no caso do armazenamento em ambiente não controlado, independente do grau de umidade da semente. Enquanto na condição de vácuo a 8,0\% e 11,0\% de umidade, as porcentagens de germinações foram de $67 \%$ e $65 \%$, respectivamente, o melhor desempenho entre as mantidas em embalagem de papel foi de $48 \%$, observado para a semente tratada (Tabela 2).

Quanto ao índice de velocidade de emergência (IVE), verifica-se pela Tabela 3 que, para a condição de câmara fria, não houve diferença entre os tratamentos, em nenhuma das épocas de avaliação, exceto pelo menor desempenho, especialmente após os 12 meses, apresentado pela semente armazenada a vácuo com $11,0 \%$ de umidade. No caso da condição de ambiente natural, o teste de vigor foi sensível a ponto de detectar quedas significativas aos seis meses de armazenamento, nos índices apresentados pela semente em embalagem plástica, independente do grau de umidade.

Em especial para o armazenamento a vácuo, o teor de água ideal da semente, ainda não está definido. Enquanto para Pessoa (1996), a porcentagem máxima não deve exceder 8,0\% para semente de milho, Bee e Barros (1999) concluíram que semente de abóbora pode ser armazenada em condições de vácuo com 13,0\% de umidade. Na condição de armazém convencional, destaca-se a superioridade do armazenamento a vácuo na umidade de $8,0 \%$, em especial aos 18 meses $(5,77)$, quando comparado ao índice de velocidade de emergência para a semente não tratada, acondicionada em embalagem de papel $(2,25)$. Verificou-se, nessa condição de ambiente, que o armazenamento a vácuo na umidade de $8,0 \%$ se manteve com os maiores índices de IVE, praticamente durante todo o período de armazenamento.

Confirmando os resultados encontrados nos demais testes fisiológicos, foi observado no teste frio, um efeito significativo para o ambiente de armazenamento, destacandose a condição de câmara fria, sobretudo a partir dos 12 meses (Tabela 4). Notou-se nessa condição, que a germinação da semente tratada e acondicionada em embalagem de papel esteve entre as mais elevadas até o final do armazenamento, provavelmente confirmando o efeito protetor do tratamento de semente relatado por Oliveira (1997), desde o início do armazenamento até os 18 meses.

$\mathrm{O}$ teste frio, por ser um teste que favorece o desenvolvimento fúngico, principalmente de Fusarium e o retardamento da germinação, foi capaz de detectar a melhor qualidade da semente tratada em relação à não tratada, nas duas condições de armazenamento utilizadas, conforme relatos de Mantovaneli (2001). Pelos resultados apresentados na Tabela 4, verificou-se maior resposta ao tratamento fungicida pela semente, nas condições de ambiente natural em relação à câmara fria, concordando com Mantovaneli (2001). Como esperado, as maiores variações no grau de umidade da semente ocorreram nos tratamentos de acondicionamento em embalagem de papel, marcadamente por uma redução no grau de umidade ao longo do armazenamento, em ambos os ambientes estudados. Nos tratamentos de armazenamento em embalagens impermeáveis, as variações no grau de umidade foram pequenas, podendo ser em parte atribuídas a oscilações ocorridas após a abertura das embalagens.

TABELA 3. Índice de velocidade de emergência(IVE) de sementes de milho doce, em função da condição de armazenamento e método de embalagem antes do armazenamento e aos 6, 12 e 18 meses. UFLA, Lavras, 2007.

\begin{tabular}{|c|c|c|c|c|c|c|c|c|}
\hline \multirow{3}{*}{ Embalagem } & \multicolumn{8}{|c|}{ Tempo de armazenamento/Condição de armazenamento } \\
\hline & \multicolumn{2}{|c|}{ Antes do armazenamento } & \multicolumn{2}{|c|}{6 meses } & \multicolumn{2}{|c|}{12 meses } & \multicolumn{2}{|c|}{18 meses } \\
\hline & Câmara fria & Ambiente & Câmara fria & Ambiente & Câmara fria & Ambiente & Câmara fria & Ambiente \\
\hline Papel tratadas & $9,52 \mathrm{aA}$ & $9,30 \mathrm{aA}$ & $9,50 \mathrm{aA}$ & $8,88 \mathrm{bA}$ & $9,48 \mathrm{aA}$ & $6,04 \mathrm{bC}$ & $8,29 \mathrm{aA}$ & $2,78 \mathrm{bD}$ \\
\hline Papel N.T.** & $9,45 \mathrm{aA}$ & $9,52 \mathrm{aA}$ & $9,41 \mathrm{aA}$ & $8,99 \mathrm{aA}$ & $9,14 \mathrm{aA}$ & $5,44 \mathrm{bC}$ & $7,92 \mathrm{aA}$ & $2,25 \mathrm{bD}$ \\
\hline Plástico $(8 \%)$ & $9,32 \mathrm{aA}$ & $9,57 \mathrm{aA}$ & $9,31 \mathrm{aA}$ & $8,23 \mathrm{bB}$ & $9,28 \mathrm{aA}$ & 8,29 bA & $8,13 \mathrm{aA}$ & $4,69 \mathrm{bB}$ \\
\hline Plástico (11\%) & $9,45 \mathrm{aA}$ & $9,08 \mathrm{aA}$ & $9,12 \mathrm{aA}$ & $8,06 \mathrm{bB}$ & $8,93 \mathrm{aA}$ & $5,57 \mathrm{bC}$ & $8,03 \mathrm{aA}$ & $3,62 \mathrm{bC}$ \\
\hline Vácuo (8\%) & $9,60 \mathrm{aA}$ & $9,34 \mathrm{aA}$ & $9,48 \mathrm{aA}$ & $8,71 \mathrm{bA}$ & $9,20 \mathrm{aA}$ & $8,70 \mathrm{aA}$ & $8,22 \mathrm{aA}$ & $5,77 \mathrm{bA}$ \\
\hline Vácuo $(11 \%)$ & $9,34 \mathrm{aA}$ & $9,32 \mathrm{aA}$ & $9,07 \mathrm{aA}$ & $8,64 \mathrm{aA}$ & $8,90 \mathrm{Aa}$ & $6,82 \mathrm{bB}$ & $7,23 \mathrm{aB}$ & $3,44 \mathrm{bC}$ \\
\hline
\end{tabular}

* Médias seguidas pela mesma letra minúscula na linha e maiúscula na coluna, dentro de cada tempo de armazenamento, não diferem entre si pelo teste de Scott e Knott para embalagem e F para condição de armazenamento $(\mathrm{P}<0,05)$.

** Papel N.T: Sementes não tratadas em embalagem de papel. 
TABELA 4. Porcentagem de germinação de sementes de milho doce no teste frio, em função da condição de armazenamento e método de embalagem, antes do armazenamento e aos 6, 12 e 18 meses. UFLA, Lavras, 2007.

\begin{tabular}{lcccccccc}
\hline \multirow{2}{*}{ Embalagem } & \multicolumn{7}{c}{ Tempo de armazenamento/Condição de armazenamento } \\
\cline { 2 - 8 } & \multicolumn{7}{c}{ Antes do armazenamento } & \multicolumn{2}{c}{6 meses } & \multicolumn{2}{c}{12 meses } & \multicolumn{2}{c}{18 meses } \\
\cline { 2 - 8 } & Câmara fria & Ambiente & Câmara fria & Ambiente & Câmara fria & Ambiente & Câmara fria & Ambiente \\
\hline Papel tratadas & $67,50 \mathrm{aA}$ & $64,50 \mathrm{aA}$ & $68,00 \mathrm{aA}$ & $52,50 \mathrm{bB}$ & $61,50 \mathrm{aA}$ & $35,00 \mathrm{bA}$ & $54,50 \mathrm{aA}$ & $28,00 \mathrm{bA}$ \\
Papel N.T.** & $69,50 \mathrm{aA}$ & $63,00 \mathrm{bA}$ & $61,00 \mathrm{aB}$ & $51,50 \mathrm{bB}$ & $53,00 \mathrm{aB}$ & $30,50 \mathrm{bB}$ & $48,50 \mathrm{aB}$ & $19,00 \mathrm{bB}$ \\
Plástico (8\%) & $61,50 \mathrm{aA}$ & $66,50 \mathrm{aA}$ & $58,50 \mathrm{aB}$ & $53,00 \mathrm{aB}$ & $55,00 \mathrm{aB}$ & $29,50 \mathrm{bB}$ & $47,00 \mathrm{aB}$ & $24,00 \mathrm{bB}$ \\
Plástico (11\%) & $64,00 \mathrm{bA}$ & $66,50 \mathrm{aA}$ & $60,00 \mathrm{bB}$ & $66,00 \mathrm{aA}$ & $52,50 \mathrm{aB}$ & $30,50 \mathrm{bB}$ & $46,00 \mathrm{aB}$ & $23,00 \mathrm{bB}$ \\
Vácuo (8\%) & $65,00 \mathrm{aA}$ & $60,00 \mathrm{bA}$ & $57,50 \mathrm{aB}$ & $42,00 \mathrm{bC}$ & $50,00 \mathrm{aB}$ & $39,00 \mathrm{bA}$ & $50,00 \mathrm{aB}$ & $33,00 \mathrm{bA}$ \\
Vácuo (11\%) & $67,00 \mathrm{aA}$ & $63,50 \mathrm{aA}$ & $61,50 \mathrm{bB}$ & $71,00 \mathrm{aA}$ & $49,50 \mathrm{aB}$ & $38,50 \mathrm{bA}$ & $52,50 \mathrm{aA}$ & $29,00 \mathrm{bA}$ \\
\hline
\end{tabular}

* Médias seguidas pela mesma letra minúscula na linha e maiúscula na coluna, dentro de cada tempo de armazenamento, não diferem entre si pelo teste de Scott e Knott para embalagem e F para condição de armazenamento $(\mathrm{P}<0,05)$.** Papel N.T: Sementes não tratadas em embalagem de papel.

Os perfis isoenzimáticos revelaram para a álcooldesidrogenase (ADH) a ausência de alteração no número e na intensidade de bandas que pudesse estar associada à redução observada na qualidade fisiológica da semente (Figura 1). Em milho, essa enzima apresenta dois locos fortemente ligados (Adh1 e Adh2), os quais são muito estudados sob o aspecto de regulação da expressão gênica por terem função definida sob condições anaeróbicas (Torggler et al., 1995). No caso do milho doce, a enzima álcool desidrogenase não se mostrou um bom indicador de redução na qualidade da semente, pois os testes fisiológicos apontaram alterações significativas nos níveis de qualidade da semente, em função dos diferentes tratamentos de armazenamento.

Para a enzima malato-desidrogenase (Figura 2) foi verificado apenas para a semente acondicionada em embalagem plástica com $11,0 \%$ de umidade e a vácuo com $8,0 \%$, ambas na condição de câmara refrigerada, o aparecimento de uma banda não presente nos demais tratamentos. Entretanto, não foram observadas correlações com alterações na qualidade fisiológica da semente. Codificadas por cinco locos, a enzima malato-desidrogenase encontra-se compartimentalizada em pequenas organelas, mitocôndrias e no citosol (Goodman e Stuber, 1987). Tal característica talvez configure uma das dificuldades no uso da ADH como um marcador seguro de alterações deteriorativas em semente. O estudo de alterações na atividade de enzimas chaves dentro do processo respiratório em semente é justificado pela hipótese de que o dano à membrana mitocondrial seria um evento primário da deterioração da semente (Fergunson et al., 1990). Desse modo, além de apresentar efeito acentuado na permeabilidade das membranas, a peroxidação dos lipídios afeta também a atividade respiratória das células, por quebrar o gradiente protônico necessário para manter o acoplamento respiratório (Wilson e McDonald, 1986).
Dentre os fungos detectados no teste de sanidade (Tabela 5), a maior incidência foi de Fusarium moniliforme e para os fungos de armazenamento Aspergilus sp e Penicilium $\mathrm{sp}$, concordando com os resultados encontrados por Jorge (2001), para semente de milho comum. Outros fungos como Cladosporium sp., Cephalosporium acremonium e Trichoderma sp. também foram identificados, em menor porcentagem. Sob condição de câmara refrigerada, a semente não tratada teve elevação na incidência de Fusarium moniliforme e Aspergillus sp e redução na incidência de Penicillium sp. Nesse caso, admite-se a hipótese de um possível efeito antagônico entre esses fungos, em condições de refrigeração com baixa umidade relativa do ar. Em contrapartida, sob condição de ambiente natural, foi observado aumento na incidência de Aspergillus sp., com correspondente diminuição nas porcentagens de Fusarium moniliforme e Aspergillus sp, durante o armazenamento. Torna-se pertinente salientar que a incidência de fungos na semente tratada e acondicionada em embalagem de papel se manteve em níveis relativamente baixos, muito próximos aos verificados no início do armazenamento, independente do ambiente em que foram armazenadas.

\section{CONCLUSÕES}

- O armazenamento sob condições de câmara refrigerada $\left(10^{\circ} \mathrm{C}\right.$ e $50 \%$ U.R $)$ é mais eficiente para a preservação da qualidade fisiológica de semente de milho doce.

- Sob condições de câmara refrigerada, o acondicionamento de semente tratada em embalagem de papel, seguido do acondicionamento em embalagem plástica, são os métodos mais eficientes para a manutenção da qualidade fisiológica da semente por 18 meses.

- Para o armazenamento de semente de milho doce, em 


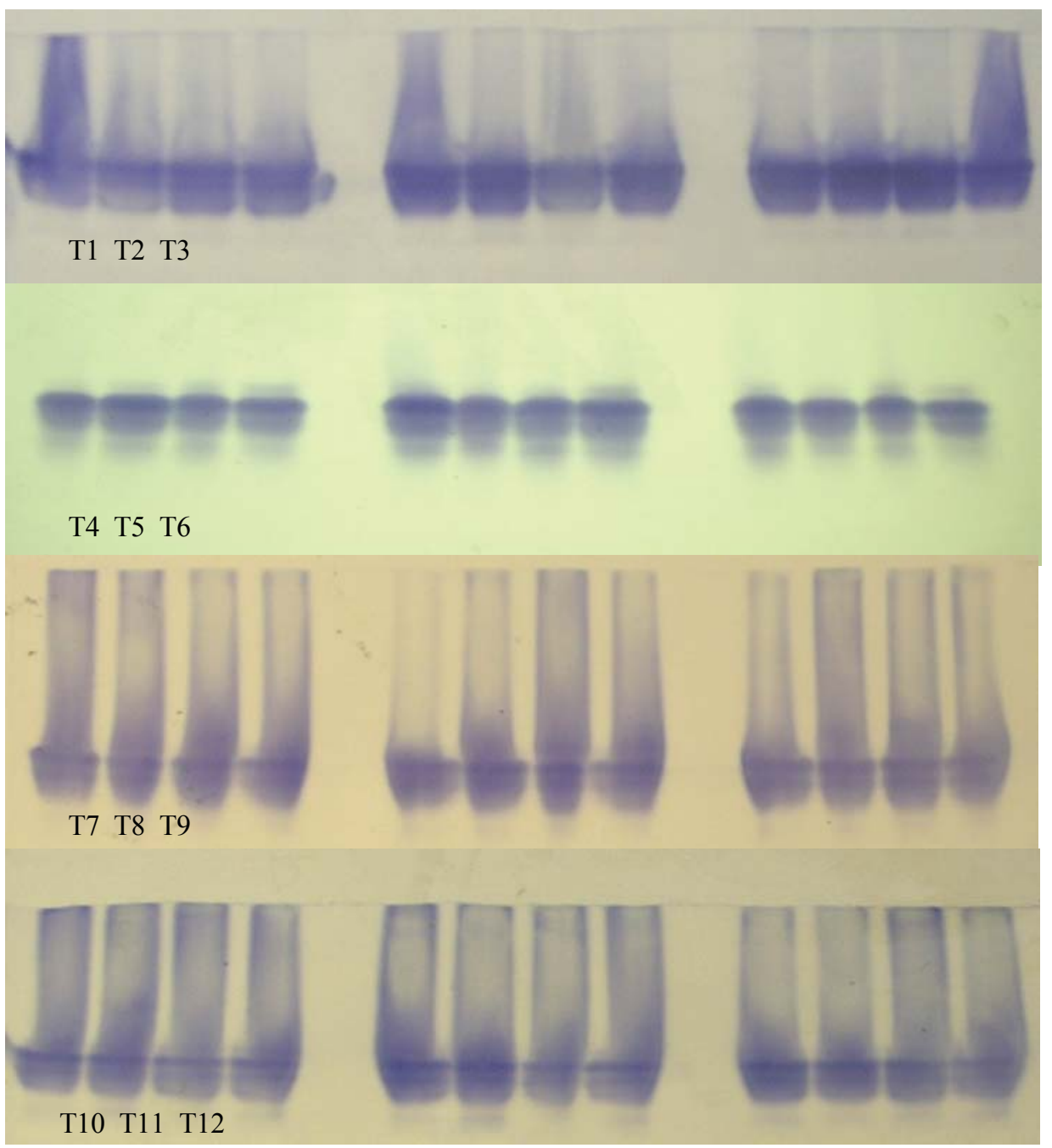

FIGURA 1. Padrões isoenzimáticos de semente de milho doce submetida a diferentes períodos (zero, seis, 12 e 18 meses) e métodos de armazenamento, reveladas para a enzima álcool desidrogenase (ADH). T1: câmara fria, papel tratada; T2: câmara fria, papel não tratada; T3: câmara fria, plástico 8,0\%; T4: câmara fria, plástico 11,0\%; T5: câmara fria vácuo 8,0\%; T6: câmara fria vácuo 11,0\%; T7: ambiente, papel tratada; T8: ambiente, papel não tratada; T9: ambiente plástico 8,0\%; T10: ambiente, plástico 11,0\%; T11: ambiente,

condições de ambiente natural, o armazenamento a vácuo em embalagem plástica com $8,0 \%$ de umidade assegura as menores reduções na qualidade fisiológica por 18 meses.

- A incidência dos fungos Fusarium moniliforme e Aspergillus sp., em ambiente de câmara refrigerada, e Aspergillus sp., em armazém convencional, é favorecida em semente de milho doce não tratada com fungicidas, independentemente do tipo de embalagem usada no armazenamento.

\section{REFERÊNCIAS}

AGUIRRE, R.; PESKE, S.T. Required bean seed moisture content for hermetic storage. Seed Science and Technology, Zürich, v. 19, p. 117-122, 1991.

ALFENAS, A.C.; PETRES, I.; BRUCE, W.; PASSADOS, G.C. Eletroforese de proteínas e isoenzimas de fungos e essências florestais. Viçosa: UFV, 1991, 242 p. 
ARAÚJO, E. F. Efeito da temperatura e umidade relativa do ar de secagem sobre a qualidade fisiológica e determinação de equilíbrio higroscópico de sementes de milho doce. 1999. 128f. Tese (Doutorado em Produção Vegetal) - UENF, Campos dos Goytacazes, 1999.

ARAUJO, E. F. et al . Maturation of sweet-corn seeds: Super Sweet group. Revista Brasileira de Sementes, Pelotas, v.28, n.2, p.69-76, 2006.

AZANZA, F.; BAR-ZUR, A.; JUVIK, J.A. Variation in sweet corn kernel characteristics associated with stand establishment and eating quality. Euphytica, Amasterdan, v.87, p. 7-18, 1996.

BEE, R.A.; BARROS, A.C.S.A. Sementes de abóbora armazenadas em condições de vácuo. Revista Brasileira de Sementes, Brasília, v. 21, p.120-126, 1999.

BRASIL. Ministério da Agricultura e Reforma Agrária. Regras para Análise de Sementes. Brasília: SNDA/DNDV/ CLAV, 1992. 365p.

CARVALHO, N.M.; NAKAGAWA, J. Sementes: ciência, tecnologia e produção. Campinas: FUNEP, 2000. 588p.

DELOUCHE, J.C.; BASKIN, C.C. Acelerated ageing techniques for predicting the relative storability of seed lots. Seed Science and Technology, Zürich, v.1, n.2, p.427-452, 1973.

EDWIN, J. Device for vacuum and inert-gas sealing of tin cans. Agronomy Journal, Welingford, v.53, p 278, 1961.

FERGUSON, J.M.; TEKRONY, D.M; EGLI, D.M. Changes during early soybean seed and axes deterioration: II. Lipids. Crop Science, Madison, v. 30, p. 179-182, 1990.

GOODMAN, M.M.; STUBER, C.W. Mayze. In: TANKSLEY, S.D.; ORTON, T.J. Isoenzimes in Plants Genetics and Breeding. (Part B), Amsterdan: Elsevier, 1987. P. 1-33.

GUISCEM, J. M.; ZUCARELI, C.; NAKAGAWA, J.; ZANOTTO, M. D. Fungos associados a sementes de milho doce das cultivares BR 400 (bt), BR 441 (su) e BR 402 (SU). Revista Brasileira de Sementes, Brasília, v. 24, n. 1, p. 247, 2001.

INTERNATIONAL SEED TESTING ASSOCIATION - ISTA. Handbook of Vigour Test Methods. Zürich, Switzerland, ISTA, 1995, 117 p.

JORGE, M.H.A. Qualidade fisiológica sanitária de sementes de milho colhidas e secadas em espiga. 2001. 86f. Dissertação (Mestrado em Agronomia/Fitotecnia) Universidade Federal de Lavras, Lavras, MG, 2001.

MAEDA, J.A.; LAGO, A.A.; MIRANDA, L.T.; TELLA,
R. Armazenamento de sementes de cultivares de milho e sorgo com resistências ambientais diferentes. Pesquisa Agropecuária Brasileira. Brasília, v.22, n.1, p.1-7, 1987.

MACHADO, J.C. Patologia de Sementes: fundamentos e aplicações. Brasília: MEC/ESAL/FAEPE, 1988. 107p.

MAGUIRRE, J. D. Speed of germination-aid seedling emergence and vivor. Crop Science, Madison, v.2, n. 2, p.176-177, Mar./Apr. 1962.

MANTOVANELI, M.C.H. Interferência de alguns fungos no teste de tetrazólio e de danos mecânicos, tratamento fungicida e do armazenamento na qualidade de sementes de milho (Zea mays L.). 2001. 173f. Tese (Doutorado em Agronomia/Fitotecnia) - Universidade Federal de LavrasMG, 2001.

MARINCEK, A. Qualidade de sementes de milho produzidas sob diferentes sistemas de manejo no campo e em póscolheita. 2000. 105f. Dissertação (Mestrado em Fitotecnia) Universidade Federal de Lavras, Lavras, MG, 2000.

MARSHALL, S.W. Sweet corn. In: Chemistry and Technology S.A. Watson and P.E. Ramstad, ed. American Association of Cereal Chemists, St. Paul, p.431-445, 1987.

NEW, J.H. Studies on vacum packing of seed. Seed Science and Technology, Zürich, v. 16, p. 715-723, 1988.

O’DOWD, E.T.; DOBIE, P. Reducing viability losses in open seed stores in tropical climates. Seed Science and Technology, Zürich, v. 11, p. 57-75, 1983.

OLIVEIRA, J.A. Efeito do método de colheita e do tipo de armazenamento na qualidade de sementes de milho. 1997. 134f. Tese (Doutorado em Fitotecnia), Universidade Federal de Lavras, Lavras: UFLA-MG,1997.

PESSOA, H.B.S.V. Produção de sementes genéticas de milho doce (Zea mays var. sacharata, L.): um exemplo com a cultivar superdoce. Informativo ABRATES, Brasília, v.6, n.1, p.62-72, 1996.

ROUZIÉRE, A. Storage of shelled groundnut seed in controlled atmosphere. I. Preliminary trials. Oleagineaux, Paris, v. 41, p. 329-344, 1986.

SMITH, M.T.; BERJAK, P. Deteriorative changes associated with the los viability of stored desications of seed associated Mycroflora during atorage. In: JAIME, K.; GALILI, G. Seed Development and Germination. New York: Basel-Hang Young 1995, p.701-746.

STYER,R.C.;CANTLIFFE,D.J.Relationshipbetweenenvironment during seed development and seed vigor of two endosperm mutant of corn. Journal of the American Society for Horticultural Science, Alexandria, v.108, n.5, p.717-720, Sept. 1983. 
TORGGLER, M.G.F.; CONTEL, E.P.B.; TORGGLER, S.P. Isoenzimas: variabilidade genética em plantas. Ribeirão Preto: Sociedade Brasileira de Genética, 1995, 186 p.

WILSON JR., D.O; McDONALD JR., M.B. The lipid peroxidation model of seed ageing. Seed Science and Technology, Zürich, v.14, n.2, p.269-300, 1986.

WILSON, D.O.; MOHAN, S.K. Seedling blight of sweet corn. Idaho Agric. Exp. Stn. Curr., 879 p. 1991. 